Editor:

LINCOLN R. MANSON-HING, D.M.D., M.S.

American Academy of Dental Radiology

School of Dentistry, University of Alabama

1919 Seventh Avenue South

Birmingham, Alabama 35233

\title{
Factors influencing the design of aiming devices for intraoral radiography and their practical application
}

\author{
J. van Aken* and J. W. Verhoeven, ** Utrecht, The Netherlands \\ DEPARTMENT OF ORAL ROENTGENOLOGY, UNIVERSITY OF UTRECHT DENTAL SCHOOL \\ Intraoral roentgenograms can be made according to the long-tube paralleling technique utilizing \\ aiming devices. These instruments consist of a bite block, an indicator rod, and a collimator plate. \\ For the position of the film in relation to the bite block surface, the following data are decisive and \\ therefore studied: the length of the teeth to be radiographed, the enlargement as a result of the \\ divergence of the $x$-ray beam, and the periapical area necessary for the interpretation and mounting \\ of the roentgenograms. As a result, the bite blocks of the instruments were provided with three \\ vertical steps to permit different film positions needed for the specific situation in the different \\ regions of the mouth. The use of the correct film positions results in roentgenograms with a high \\ diagnostic value. In order to reduce the patients radiation dose the aiming devices include a \\ collimator plate. A description is given of the data used for the design of the plate.
}

$I_{1}$ In intraoral radiography the most desirable projection of the teeth is obtained when (1) a parallel x-ray beam is used, (2) the beam is directed at right angles to the tooth axis, and (3) the film is placed at right angles to the beam. ${ }^{1}$ To permit the interpretation of the periapical area of a tooth, ${ }^{4}$ the film should extend $3 \mathrm{~mm}$. beyond the projection of the apex on the plane of the film. ${ }^{1-4}$ These principles have to be modified to meet practical situations. Modifications are needed because of the beam divergence, which depends on the focal spotobject distance, and because of the anatomic structures (palate, floor of the mouth) which often prevent the film from being placed in the desired position. As a result of these two factors, the image projection is changed as illustrated in Fig. 1.

For many years aiming devices and long-cone $\mathrm{x}$-ray

\footnotetext{
*Ilead, Department of Oral Roentgenology, University of Utrecht Dental School

**Staff Member, Department of Oral Roentgenology, University of Utrecht Dental School.
}

machines have been used, based on the above mentioned principles. Aiming devices for this technique were initially designed by W. J. Updegraves (X.C.P. Instruments), followed by J. van Aken' ("model Utrecht') and others. A complete set of these aiming devices for periapical radiography, as used at the University of Utrecht Dental School, consists of one anterior and two posterior instruments. Each instrument is composed of a bite block designed to hold the film packet, an indicator rod, and a collimator plate (Fig. 2).

With the use of aiming devices, the apical border of the film packet is placed in contact with the palate or the floor of the mouth and the bite block against the occlusal surfaces of the teeth to be radiographed. By changing the position of the aiming device, without losing these two contacts, a position is selected which results in a direction of the $\mathrm{x}$-ray beam with the smallest possible deviation from the ideal direction, angle $\alpha$. (Fig. 1). The instrument is held in position by the force 


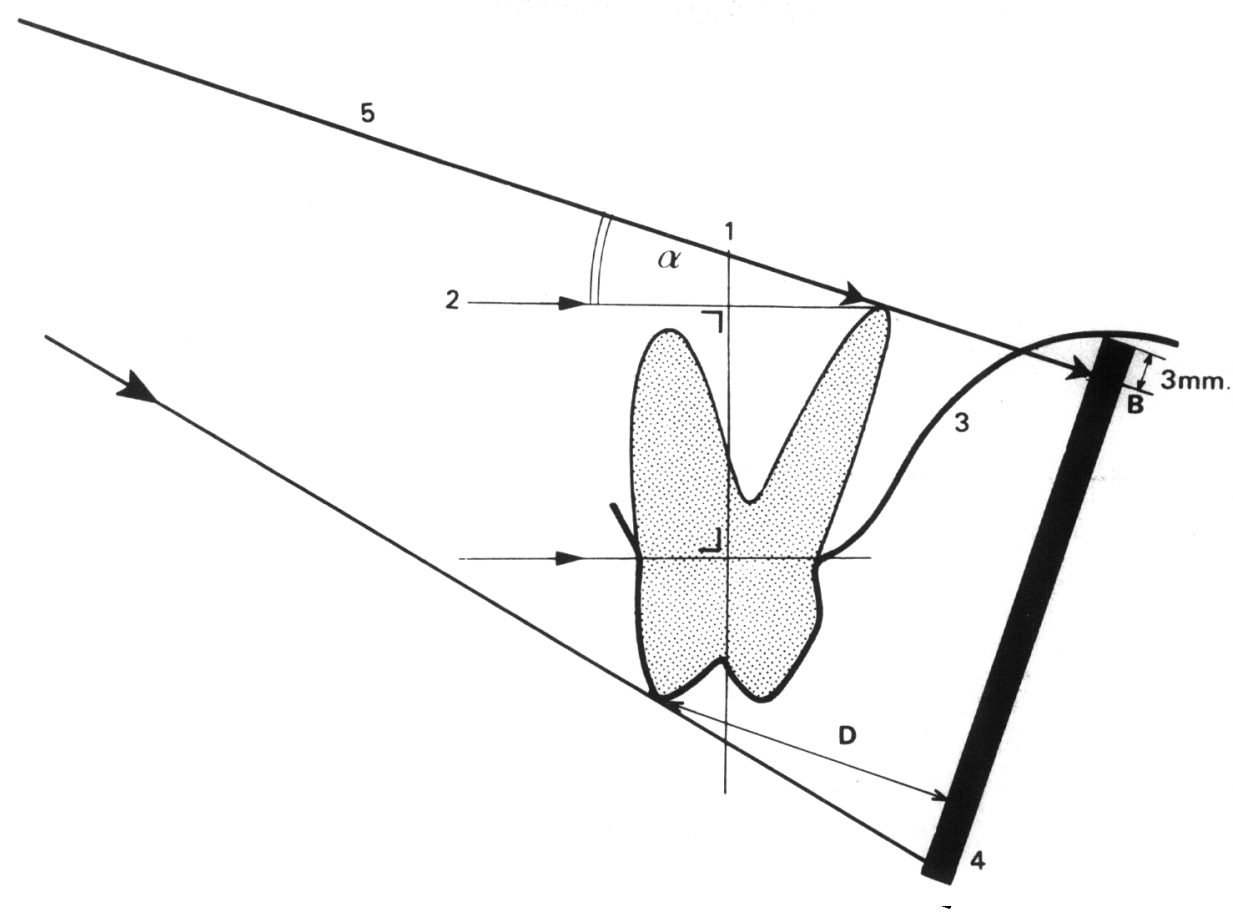

Fig. 1. The deviation of the $\mathrm{x}$-ray beam from the ideal direction (angle $\alpha$ ). $/$, Long axis of the tooth to be radiographed. 2. Ideal direction of the $x$-ray beam (perpendicular to / 3, Palate. 4. Film position with the palatal apex projected at a distance of $3 \mathrm{~mm}$. from the film border $(B) .5$, Ray projecting the palatal apex in $B$. $D$. Object-film distance.

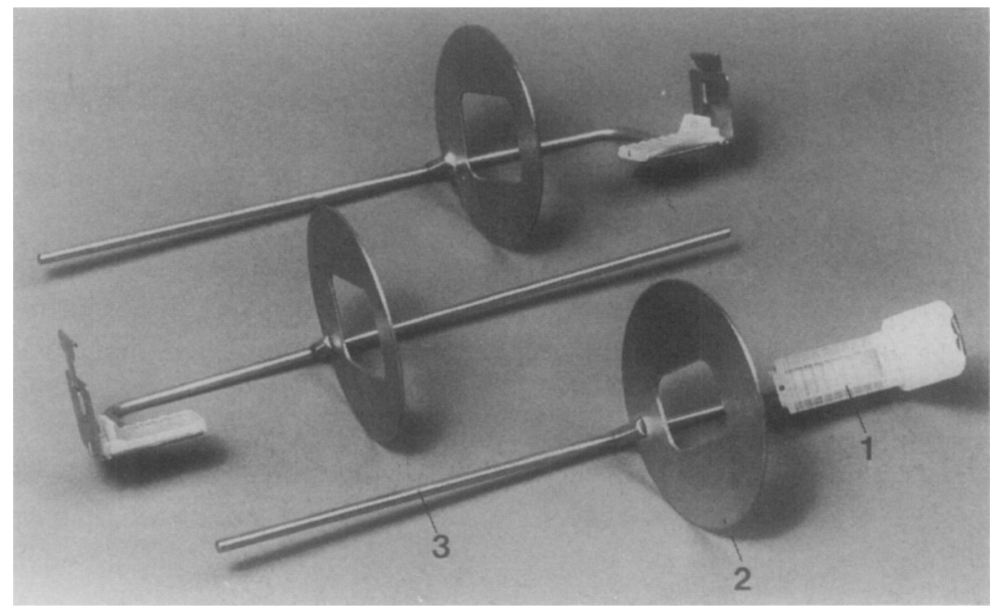

Fig. 2. Complete set of aiming devices used at Utrecht University Dental School. 1. Bite block. 2, Collimator plate. 3. Indicator rod.

exerted by the opposing teeth. The direction and position which should be given to the tube of the $x$-ray unit are automatically shown by the indicator rod and collimator plate.

The use of these instruments and a long-tube $x$-ray machine results in a procedure in a close agreement with requirements 1 and 3 (a parallel $x$-ray bean perpendicular to the film). The amount of tilting of the instrument depends on two factors: (1) the anatomic structures, which prevent the film from reaching the ideal position, and (2) the amount of film, which extends above the plane of the bite block (Fig, 3, $H$ ).

As described in the literature, ${ }^{1,4} \tau$ the size of the angle between the ideal and the applied beam direction, i.e., the tilting, which is given the symbol $\alpha$ (Fig. 1), has a decisive influence on the image formation and should be kept as small as possible. Since anatomic structures cannot be changed, the only reduction of $\alpha$ 


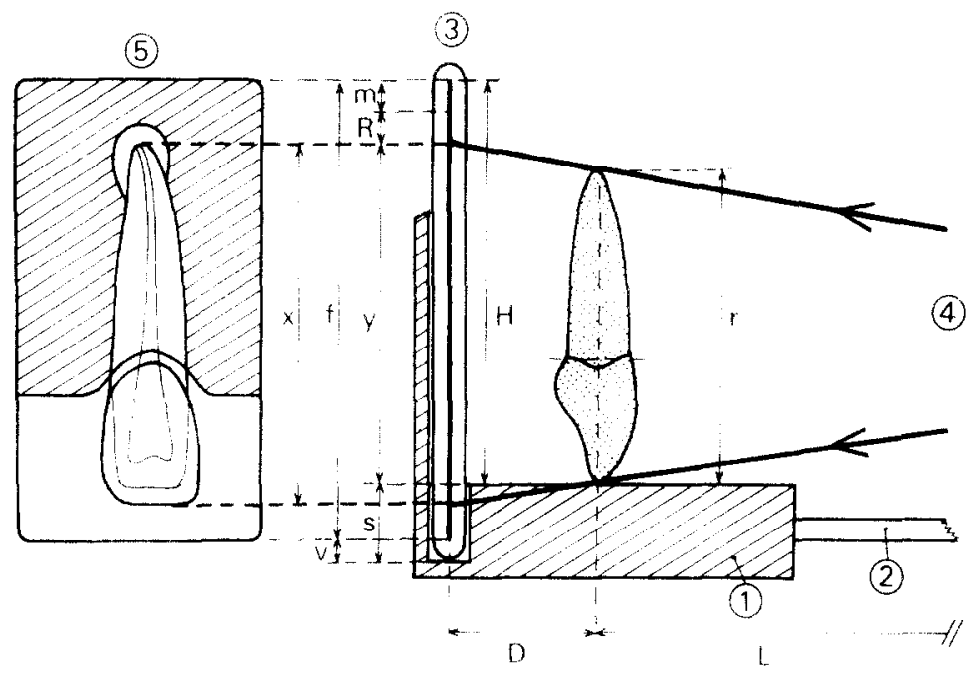

Fig. 3. Image formation utilizing the long tube paralleling technique with atiming devices. $/$. Bite block of the aiming device. 2, Indicator rod. 3. Radiographic film. t. Incident $x$-ray beam. 5, Resulting roentgenogram. $r$. Length of the tooth to be radiographed. $L$. Focial spot-object distance. $D$. Object-tilm distance, $x$, Length of the image of the tooth on the roentgenogram. I I neth of the part of the image projecting above the bite block. $R$, Periapical area. $m$. Mounting space (unilateratl. $H$. Length of the part of the tilm projecting above the occlusal surface of the bite block, f. Film size. 4. Cnilatetial thickness of the tilm package material. s. Part of the film packet submerged in the hite block.

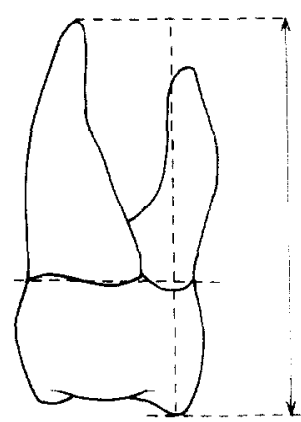

a

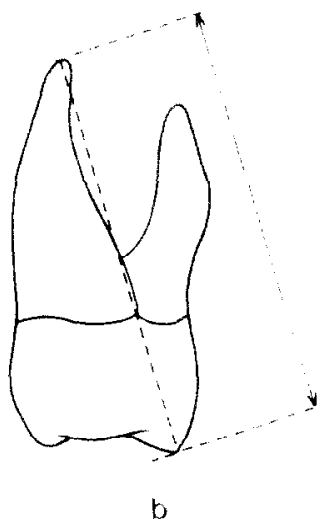

Fig. 4. The length of a maxillary molar. a. The length of the terth. measured perpendicularly to the connecting line of the buccal and palatal borders of the crown. $b$. The length that is relevant for radiologic purposes.

can be obtained by reducing the amount of tilm extend. ing above the bite block. In all situations. however, an area of $3 \mathrm{~mm}$. beyond the tooth apex should be visible on the mounted roentgenogram

The desired film position in the aiming device can therefore be defined as the position in which the dis tance from the apical border of the mounted film to the bite plane is $3 \mathrm{~mm}$. larger than the maximum distanc: (y), which can occur between the image of the atpex and the bite plane (Fig. 3).

This distance $y$ is found when the tooth axis is perpendicular to the ray projecting the apex (Fig. 10, b) Note that tilting the instrument is equivalent to tiling the tooth in relation to the bite block. Since differcent teeth in the patient's mouth have different lengths, the desired film position depends on these tooth lengths and. as a conscquence, different film positions are reyuired for the different areas of the mouth.

The purpose of this investigation was to collect and apply data for improving the existing aiming devices, "model Utrecht." Factors influencing the design of the following components of the instruments were considered:

1. The bite block. For the above-mentioned reasons the bite block should permit film positions resulting in different values for the distance $H$ (Fig. 3). They should be adapted to the length of the teeth to be radiographed.

2. The collimator plate. For reasons of radiation protection, this additional diaphragm should restrict the $x$-ray beam to a field size matching the specific film size used.

\section{MATERIALS AND METHODS The design of the bite block}

In order to meet the requirements as explained in the introduction. the distance $\mathrm{H}$ should be determined. From Fig. 3 it can be concluded that the distance $H$ can be found by adding $y, m$, and $R, R$ being the periapical view needed for the interpretation and $m$ the width of the margin of the film covered by the mounting system. The distance $y$ can be found by multiplying the roentgenologic relevant length of the teeth in the pertinent region (1) with the ratio $\frac{y}{r}$. According to the formula for determing $\frac{y}{r}$ as given in the appendix, the 
Table I. The roentgenologic relevant length (r.r.l. $=r$ ) of the teeth in the different regions of the mouth (mm.)

\begin{tabular}{c|c|c}
\hline \multirow{2}{*}{ Region } & \multicolumn{2}{|c}{ Roentgenologic relevant length $(\mathrm{mm})}$. \\
\cline { 2 - 3 } & Male & Female \\
\hline Maxilla & & \\
Incisors & 28.5 & 26.3 \\
Cuspid & 32.8 & 30.8 \\
Premolars & 26.8 & 24.8 \\
Molars & 27.0 & 25.5 \\
\hline Mandible & & \\
Incisors & 27.0 & 24.8 \\
Cuspid & 32.8 & 28.8 \\
Premolars & 26.8 & 25.0 \\
Molars & 26.0 & 25.8 \\
\hline
\end{tabular}

distance from focal spot to object $(\mathrm{L})$ and the objectto-film distance (D) should be known.

The length of the teeth to be radiographed. For this purpose, accurate information on the length of the teeth in the different regions of the mouth is essential. In making a full mouth radiographic survey the following regions can be distinguished in the maxilla and mandible: the incisor area, the cuspid area, the premolar area, and the molar area. Reliable data regarding the length of the teeth in these areas were not available from the literature and were therefore collected and are presented in an earlier report. ${ }^{*}$

The measurements were made on extracted teeth collected in the central part of The Netherlands by dentists in their private practice, in clinics of the National Health Service, the military service, and a dental school. Fifty specimens of each tooth type, except the third molars, were studied, giving a total of $50 \times 7$ (tooth type) $\times 2$ (maxilla and mandible) $\times 2$ (males and females) $=1.400$ teeth. (For details, see the preceding report. ${ }^{8}$ ) The dimension which is responsible for the length of the image on the $x$-ray film was measured (Fig. 4). From these values the roentgenologic relevant length ( $r . r . l .=r$ ) was obtained by taking the maximum length value of the teeth in each region after excluding 5 percent of extremes. Table $1^{*}$ gives, for both sexes, these roentgenologic relevant lengths of the teeth in the different regions of the mouth. All length differences between the teeth of males and females are statistically significant. The exclusion of 5 percent of extremes will guard against missing the apices too often on the roentgenogram. As a result, it will frequently occur, however, that angle $\alpha$ is somewhat larger than is required for an optimal image formation' (Fig. 5).

* It may be possible that data collected from other racial groups will result in other values for the dimension $r$.

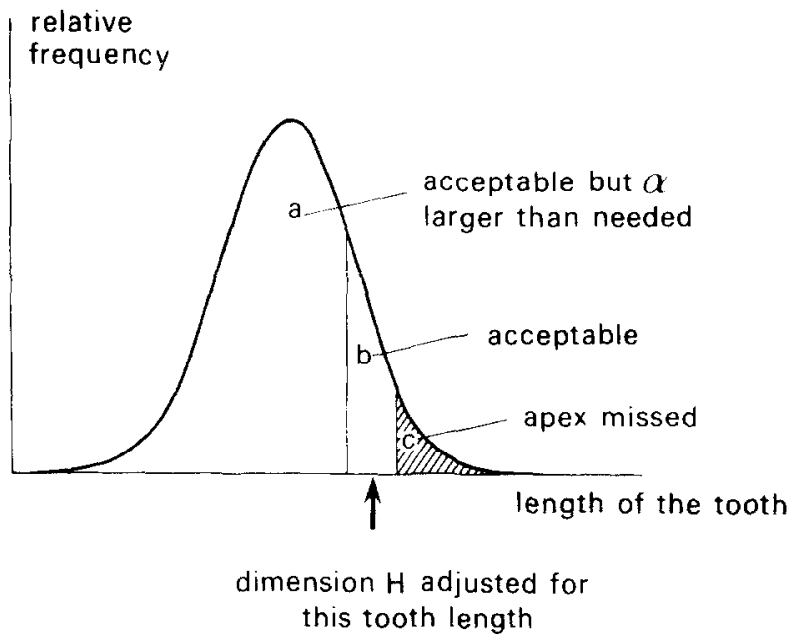

Fig. 5. Probability (when $\mathrm{H}$ is adjusted for the indicated tooth length) of $a$, making a roentgenogram with an $\alpha$ larger than is needed; $b$, making a roentgenogram with an acceptable vertical angulation; and $c$ missing the apex on the film.

Factors $D$ and $L$. For each region of the mouth, the mean object-film distance (D) was measured in a group of five male and five female patients. Since the use of the aiming devices results in a constant focal-spot-tofilm distance $(\mathrm{D}+\mathrm{L})$, the focal spot-to-object distance can be found by subtracting $D$ from the distance $D+\mathrm{L}$. The focal-spot-to-film distance $(\mathrm{D}+\mathrm{L})$ was determined by the following three components:

1. The distance from the focal spot to the end of the tube, which was set at $300 \mathrm{~mm}$. This distance exceeds the minimum required ${ }^{1}$ to avoid excessive image distortion.

2. A space of $5 \mathrm{~mm}$. between the collimator plate and the tube end, which was used to avoid interference between the $x$-ray machine and the aiming device.

3. The distance between the collimator plate and the film, which was fixed at $95 \mathrm{~mm}$. to prevent interference of the collimator plate with the patient's face.

These three values result in a focal-spot-to-film distance of $400 \mathrm{~mm}$.

The periapical area $(R)$. For the correct interpretation of the periapical area, a minimum of $3 \mathrm{~mm}$. beyond the tooth apex is found acceptable in many publications. ${ }^{1-+}$ Therefore, $3 \mathrm{~mm}$. was used as a standard distance for R (Fig. 3).

The film mounting space $(m)$. This amount was determined by measuring different types of commercially available mounting systems.

\section{The design of the collimator plate}

The purpose of this additional diaphragm is to restrict the $x$-ray beam to a field size matching the 


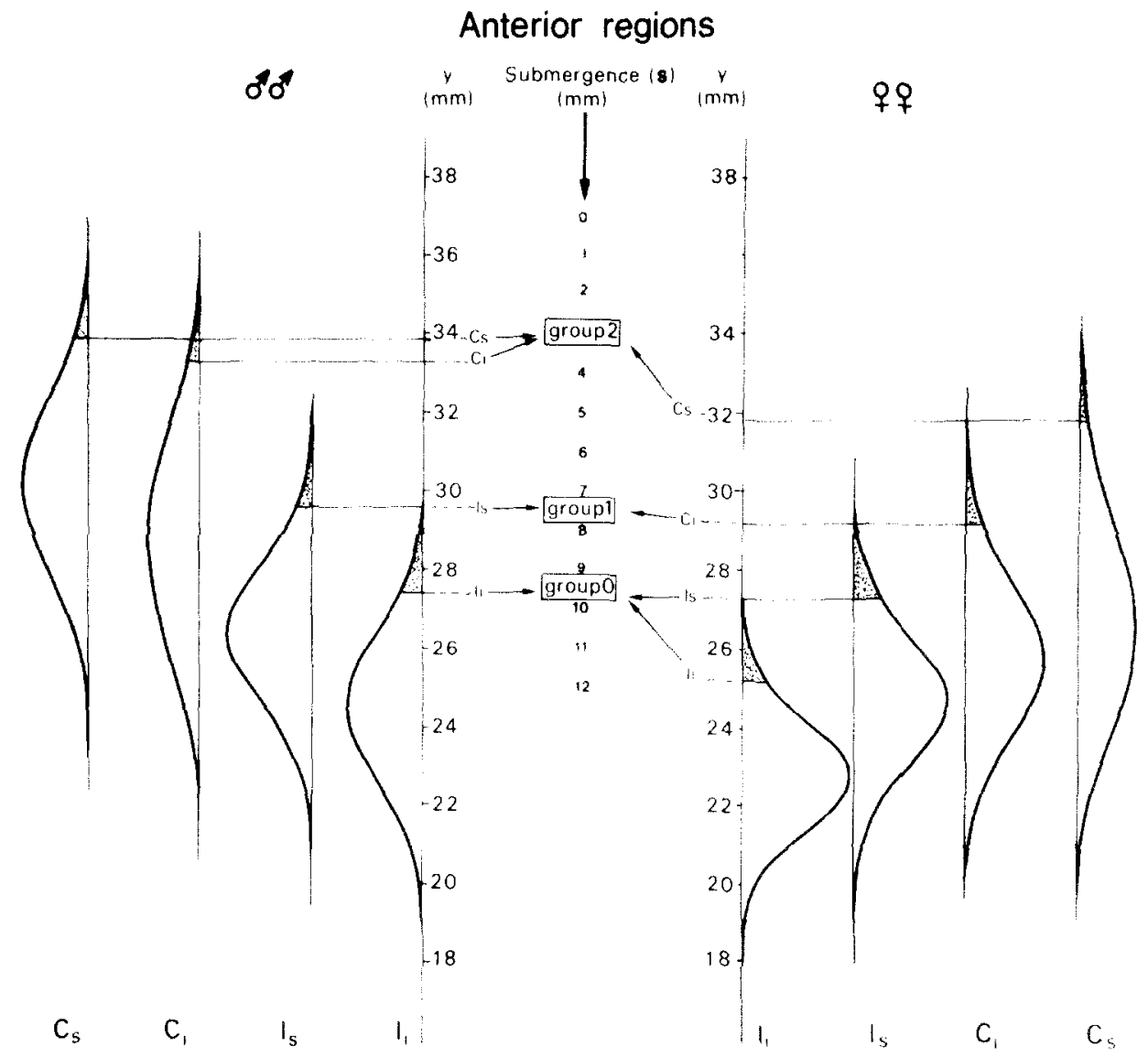

Fig. 6A. Anterior regions. For all regions, anterior (A) and posterior (B), the theorerically expected normal distributions of the distance of the projection of the apex to the bite block (y) are given. The shaded area corresponds with the 5 percent extreme values which were excluded when the roentgenologic relevant length (r) was determined. According to formula 3 (appendix 2) there is a linear relationship between $y$ and $s$. which permits the introduction of an scale in the same graph. The film submergence groups as given in Table IV are also indicated.

Table II. The object-film distance (D), the focal spot-object distance (L), and the ratio $\frac{y}{r}$ in radiographing the teeth in the different regions of the mouth

\begin{tabular}{l|c|c|c}
\hline Region & $D(\mathrm{~mm})$. & $L(\mathrm{~mm})$. & ratio $\%$ \\
\hline Maxilla & & & \\
Incisors & 29 & 371 & 1.039 \\
Cuspid & 25 & 375 & 1.033 \\
Premolars & 13 & 387 & 1.017 \\
Molars & 13 & 387 & 1.017 \\
\hline Mandible & & & \\
Incisors & 12 & 388 & 1.015 \\
Cuspid & 11 & 389 & 1.014 \\
Premolars & 12 & 388 & 1.015 \\
Molars & 12 & 388 & 1.015 \\
\hline
\end{tabular}

$D=$ Object-film distance; for premolars and molars, this distance was measured from the top(s) of the buceal cusp(s) to the film surface.

$\mathrm{L}=$ Corresponding focal spot-object distance.

$D+L=400 \mathrm{~mm}$. specific film size used. The following aspects were considered:

The material used for the construction and its thickness. For sterilization. stainless steel was used for the main parts of the instrument except for the bite blocks, which had to be radiolucent in order to transmit the radiation necessary for image formation.

The necessary thickness of the collimator plate depends on the type of material, which is used for the construction, the applied $\mathrm{kVp}$, and the accepted percentage of transmission of the incident radiation. The attenuation was read from radiation transmission curves for two radiation qualities $(60 \mathrm{kVp}$ and $90 \mathrm{kVp}$. both with a total filtration of $2 \mathrm{~mm}$. aluminum).

The size of the collimator plate. The diameter of the circular collimator plate was based on the ICRP $^{9}$ requirements for the radiation field diameter at the end of the tube of dental $x$-ray units.

The dimensions of the opening in the collimator plate were determined by the distance from collimator plate to film, which is $95 \mathrm{~mm}$.; the distance from focal spot 


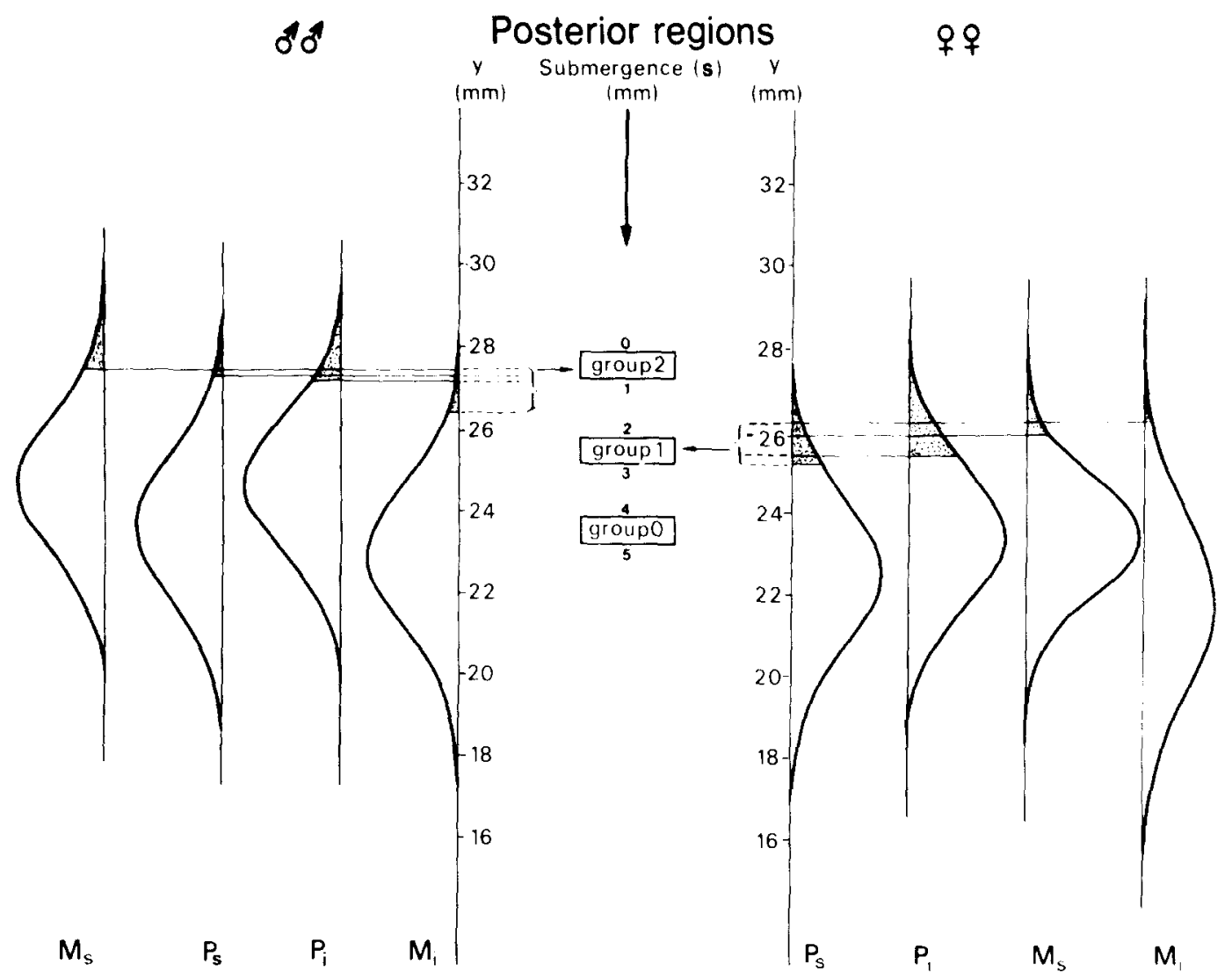

Fig. 6B. Posterior regions. (For details, see legend to Fig. 6A.)

to film, which is $400 \mathrm{~mm}$; and the size and position of the film used.

For the anterior instrument, which is used with size 1 films, ${ }^{10}$ the opening was given a dimension, which produced no annoying cone cutting with an accurate alignment of the cone of the $x$-ray machine. For the posterior instruments, which are used with Size 2 films, ${ }^{10}$ a relatively larger opening was accepted to permit a distally eccentric position of the film packet in the bite block to facilitate radiographing the third molars with little discomfort for the patient. This distal eccentric film position requires an asymmetrical opening in the collimator plate, which is somewhat larger than is necessary to avoid cone cutting with the film placed centrally in the bite block.

\section{RESULTS AND DISCUSSION The design of the bite block}

For optimal image formation, the dimension $\mathrm{H}$ (that is, the amount of film that should be above the occlusal surface of the bite block of the aiming device) is decisive (Fig. 3). As explained, the distances $r, D$, and $L$ have to be known to find $\mathrm{y} . \mathrm{H}$ is found by adding $\mathrm{y}, \mathrm{R}$. and $m$ (Fig. 3). With a constant distance from the film to the contact point of the tooth with the bite block (D), the position of the projection of the apex of a tooth changes with the angulation of the aiming device rela- tive to the tooth $(\alpha)$. This change results in a change of the distance from the projected apex to the bite block surface $(y)$ (Fig. 10).

It can be shown that the difference between the maximum value for $y$ (reached when the ray projecting the apex is perpendicular to the r.r.l.), $y^{\prime}$, and the value found when the direction of the r.r.l. is perpendicular to the bite block $y$ is only 0.1 percent of the distance $y$. The maximum of the absolute difference, which can be found with the maximum tooth length, is only 0.03 $\mathrm{mm}$. (For formulas see Appendix 1.) This difference can be neglected, and all calculations were therefore based on a tooth position in which the r.r.l. is perpendicular to the surface of the bite block (Figs. 3 and 10).

The distance $y$. The roentgenologic relevant length (r.r.l. $=r$ ) values for the different regions of the mouth are given in Table 1 . The ratio $\frac{y}{r}$ (Table II) was calculated for each region of the mouth using $400 \mathrm{~mm}$. for the distance from focal spot to film $(D+L)$ and the data collected for the object-film distance (D). (See Appendix 1A.) The values for D given in Table II are the average of ten measurements. The range in these measurements was approximately $5 \mathrm{~mm}$. Differences between values are the result of variations in the anatomy which influenced positioning of the aiming device (Fig. 1).

Table III presents, for each region of the mouth, 
Table III. The dimensions of $y, R$ (periapical view), $m$ (mounting space), H, and $s$ (submergence of the film packet) for the teeth in the different regions of the mouth $(\mathrm{mm}$.)

\begin{tabular}{|c|c|c|c|c|c|c|c|c|c|c|}
\hline \multirow[b]{2}{*}{ Region } & \multicolumn{5}{|c|}{ Male } & \multicolumn{5}{|c|}{ Female } \\
\hline & $y$ & $R$ & $m$ & $H$ & $s$ & $y$ & $R$ & $m$ & $H$ & $s$ \\
\hline \multicolumn{11}{|l|}{ Maxilla } \\
\hline Incisors & 29.6 & 3 & 1.75 & 34.35 & 7.4 & 27.3 & 3 & 1.75 & 32.05 & 9.7 \\
\hline Cuspid & 33.9 & & & 38.65 & 3.1 & 31.8 & & & 36.55 & 52 \\
\hline Premolars & 27.3 & & & 32.05 & 0.7 & 25.2 & & & 29.95 & 2.8 \\
\hline Molars & 27.4 & & & 32.15 & 0.6 & 25.9 & & & 30.65 & 21 \\
\hline \multicolumn{11}{|l|}{ Mandible } \\
\hline Incisors & 27.4 & 3 & 1.75 & 32.15 & 9.0 & 25.2 & 3 & 1.75 & 29.95 & 11.8 \\
\hline Cuspid & 33.3 & & & 38.05 & 3.7 & 29.2 & & & 33.95 & 7.8 \\
\hline Premolars & 27.2 & & & 31.95 & 0.8 & 25.4 & & & 30.15 & 2.6 \\
\hline Molars & 26.4 & & & 31.15 & 1.6 & 26.2 & & & 30.95 & 1.8 \\
\hline
\end{tabular}

See also Fig. 3

Table IV. Classification of the anterior and posterior regions of the mouth into groups requiring different film packet submergences (s)

\begin{tabular}{|c|c|c|c|}
\hline $\begin{array}{l}\text { Anterior } \\
\text { regions }\end{array}$ & $\begin{array}{c}\text { Group 0 } \\
(s=9.5 \mathrm{~mm})\end{array}$ & $\begin{array}{c}\text { Group }) \\
(\mathrm{s}=7.5 \mathrm{~mm} .)\end{array}$ & $\begin{array}{c}\text { Group } 2 \\
(s=3 \mathrm{~mm} .)\end{array}$ \\
\hline $\begin{array}{l}\text { Maxilla } \\
\text { Incisors } \\
\text { Cuspid }\end{array}$ & $r$ & $\because$ & $\therefore \quad \therefore$ \\
\hline $\begin{array}{c}\text { Mandible } \\
\text { Incisors } \\
\text { Cuspid }\end{array}$ & 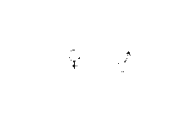 & $=$ & $\therefore$ \\
\hline $\begin{array}{l}\text { Posterior } \\
\text { regions }\end{array}$ & $\begin{array}{c}\text { Group } 0 \\
(s=4.6 \mathrm{~mm} .)\end{array}$ & $\begin{array}{c}\text { Group } / \\
(\mathrm{s}=2.6 \mathrm{~mm} .)\end{array}$ & $\begin{array}{c}\text { Group } 2 \\
(s=0.6 \mathrm{~mm} .)\end{array}$ \\
\hline $\begin{array}{l}\text { Maxilla } \\
\text { Premolars } \\
\text { Molars }\end{array}$ & & $\because$ & $\vdots$ \\
\hline $\begin{array}{l}\text { Mandible } \\
\text { Premolars } \\
\text { Molars }\end{array}$ & & $\therefore$ & $\therefore$ \\
\hline
\end{tabular}

separately for males and females. the resulting value for $y$ (Figs. 3 and 10). These length values are obtained by multiplying r (r.r.l.. Table I) by the corresponding ratio $\frac{y}{r}$ values as presented in Table II.

The periapical area $(R)$. As explained, the periapical area needed for interpretation can be set at $3 \mathrm{~mm}$.

The film mounting $(\mathrm{m})$. For ten commercially available mounting systems, half the difference between the vertical dimension of the film type and the corresponding dimension of the opening in the mounting system was determined. It was found that approximately 1 to 2 $\mathrm{mm}$. of the border of the film is covered by the mounts (mean value, $1.75 \mathrm{~mm}$.). It was noticed, however, that for some mounting systems there is a great difference between the occlusal and the apical film coverage as a result of asymmetrical film positioning behind the opening of the mount. Unilateral values up to $4 \mathrm{~mm}$. were occasionally found.

Since the mounting systems. which cover only a small area of the film, have been shown to be reliable in use, it was decided to use the average valuc of 1.75 $\mathrm{mm}$. for the distance $\mathrm{m}$.

The resulting distance $H$. In Table III the dimensions $\mathrm{R}$ and $\mathrm{m}$ are given, as well as the distance $\mathrm{H}$ for each region of the mouth. These values were obtained by adding $\mathrm{R}$ ( $3 \mathrm{~mm}$ of periapical view) and $m(1.75 \mathrm{~mm}$. of mounting space) to $y$.

Means of reali-ing the different film positions $(H)$. In order to give films of standard size the correct vertical position ( $\mathrm{H}$ ). a partial submergence ( $s$ ) in the bite block of the aiming device is necessary. This distance $(s)$ can be found by using the following equation:

$$
\text { ( } 1 \text { - H }+v \text { (sce Fig. 3) }
$$

in which $\mathrm{l}$ is the relevant film dimension and $v$ the unilateral thickness of the tilm packing material. Both values can be taken from ISO $3665 .^{10}$ For film No. 1 used for the front area, $f$ is $40 \mathrm{~mm}$.: for film $\mathrm{No} .2$ used for the lateral area, $f$ is $31 \mathrm{~mm}$. In all cases $v$ is 1.75 $\mathrm{mm}$. For $\mathrm{H}$, see Table III. The result of this procedure is included in Table III.

Since it is rather impractical to introduce eight different film positions in each aiming device. it was decided to accept a maximum of three different positions. These positions were as close as possible to the theoretical values (Fig. 6). The tinal result is presented in Table IV. In this procedure differences of tenths of at millimeter were neglected. The anterior and the posterior regions are treated separately. because for these areas different aiming devices and different film types are used

Fig. 7 illustrates the bite block of the aining device 


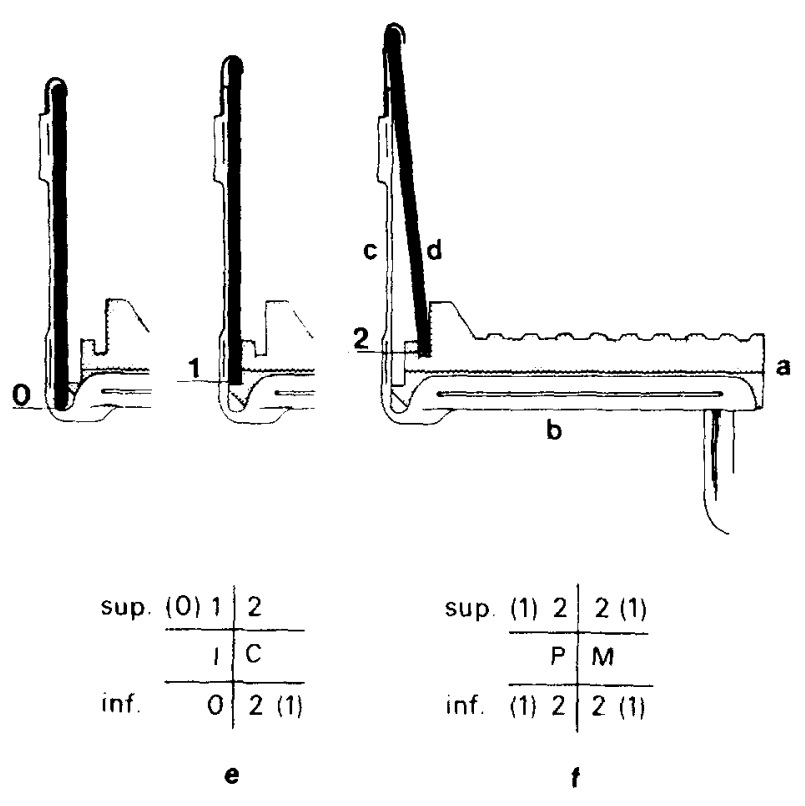

Fig. 7. Provisions made in the bite block to realize the described film positions (see Fig. 6). These positions depend on the length of the teeth in the region to be radiographed. Components of the bite block: $a$, Plastic part of the bite block. $b$, Stainless steel guidance. $c$, Backing plate of the bite block. $d$, Film. Diagram of the classification for film packet positions for the different regions of the mouth. This diagram is reproduced on the collimator plates of the anterior $(e)$ and posterior ( $f$ ) aiming device.

and the different film positions. The classification of film positions is indicated schematically on the collimator plate (Fig. 7). For females, the film positions indicated between parentheses can be used. In all other cases the same position is required for males and females. The use of the indicated film positions makes it possible to obtain roentgenograms with a deviation from the ideal direction of the $x$-ray beam (angle $\alpha$ ) which is as small as possible. The percentage of films which do not show enough of the periapical area will be less than 5 percent.

Fig. 8 shows two roentgenograms of the mandibular incisor-cuspid region made with films in positions 0 and 2 . The roentgenogram made with the film in position 0 is appropriate for the incisor region but gives an insufficient periapical view of the cuspid. The roentgenogram made with the film in position 2 gives a sufficient periapical view of the cuspid, but the image of the incisors is distorted as demonstrated by the image of the metal wire which was attached to the cementoenamel junction of the tooth. This distortion is the result of the large angle $\alpha$ caused by the inappropriate film positioning in the bite block.

When it is noticed on a roentgenogram of an individual patient that a tooth deviates considerably from the r.r.l., the film position can be adjusted accordingly

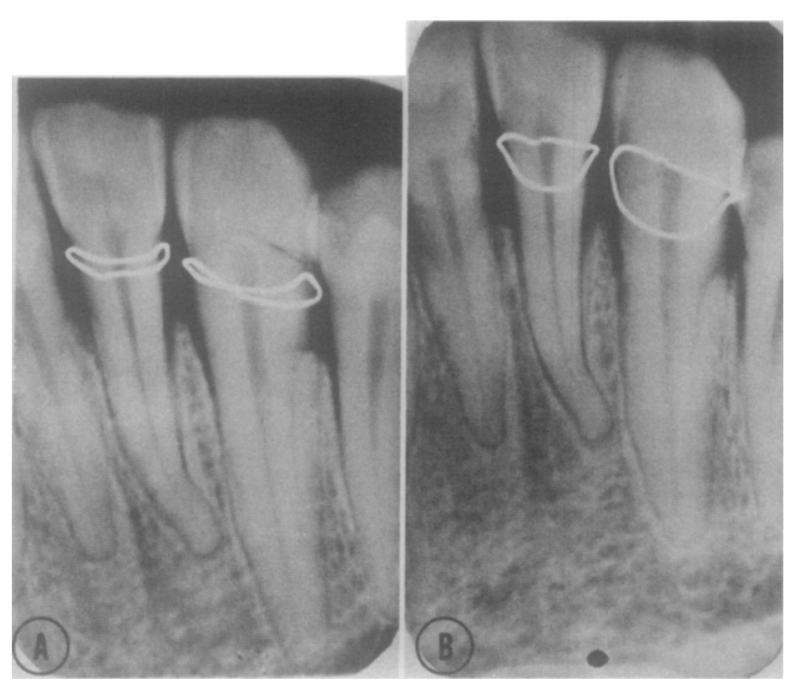

Fig. 8. lmage of a mandibular incisor-cuspid region as visible on the mounted $x$-ray film. Cervical border of the crown is marked with a metal wire. A, Inage obtained with film position 0--appropriate for the incisor region. B, Image obtained with film position 2-appropriate for the cuspid

for future roentgenograms of this tooth by changing the step on which the film is positioned.

\section{Design of the collimator plate}

The thickness of the collimator plate. The attenuation of the primary beam by the material used for the construction of the collimator plate was determined for $60 \mathrm{kVp}$ and $90 \mathrm{kVp}$ (Fig. 9). A material thickness of $1.4 \mathrm{~mm}$. of stainless steel was accepted to give a sufficient attenuation of the incident radiation. This thickness transmits 1.45 percent of the radiation generated at $60 \mathrm{kVp}$ and 6.7 percent of the radiation produced at $90 \mathrm{kVp}$.

The size of the collimator plate. X-ray units, which meet the requirements of the ICRP.9 have "a radiation field diameter at the cone end that should not exceed 6 $\mathrm{cm}$. and that shall not exceed $7.5 \mathrm{~cm}$." From these data it was concluded that a circular plate with a diameter of $78 \mathrm{~mm}$. is large enough to shield the prinary beam.

The dimensions of the opening in the collimator plate. For the anterior aiming device. which is used with Size 1 films ( 24 by $40 \mathrm{~mm}$.), the dimensions of the opening are 23.6 by $36.6 \mathrm{~mm}$. This opening produces an irradiated area at the film site of 31.0 by $48.0 \mathrm{~mm}$. . leaving play for the different film positions and small inaccuracies $(3 \mathrm{~mm}$.) of the alignment. As a result, 64.5 percent of the transmitted radiation is used to expose the film.

The posterior instruments permit about a $6 \mathrm{~mm}$. distally eccentric position of the film in the bite block. This was found to be sufficient to permit radiographing of the third molars. The dimensions of the opening in 


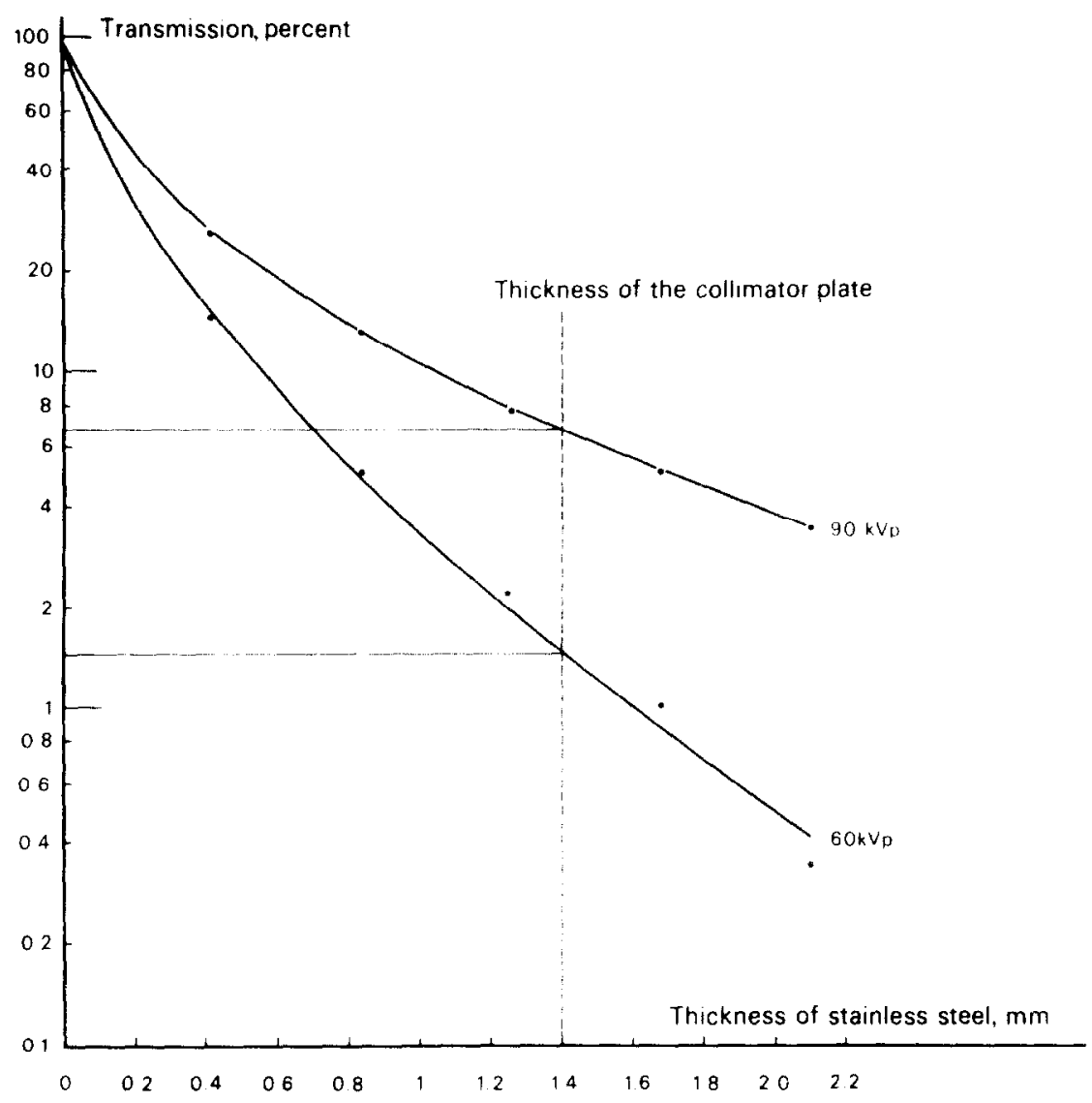

Fig. 9. Radiation transmission curves for stainless steel. X-ray unit: Philips Practix 9o/20. Tube potential: $60 \mathrm{kVp}$ and $90 \mathrm{kVp}$. Total filtration: $2 \mathrm{~mm}$. aluminum.

Table V. Percentage of radiation of the useful beam exposing the film (focal spot to tube end distance, $300 \mathrm{~mm}$.; tube end to film distance, $100 \mathrm{~mm}$.; field sizes measured at tube end).

\begin{tabular}{|c|c|c|c|c|}
\hline \multirow[b]{3}{*}{$\begin{array}{l}\text { Percent of the } \\
\text { radiation used }\end{array}$} & \multicolumn{2}{|c|}{ Field size without collimator plate } & \multicolumn{2}{|c|}{ Field size with collimator plate } \\
\hline & \multicolumn{2}{|c|}{ Circular } & \multicolumn{2}{|c|}{ Rectangular area } \\
\hline & $\begin{array}{l}\phi 60 \mathrm{~mm} \\
I C R P^{9} \mathrm{~min}\end{array}$ & $\begin{array}{l}\phi 75 \mathrm{~mm} . \\
I C R P^{9} \max .\end{array}$ & $23.6 \times 36.6 \mathrm{~mm}$. & $30.5 \times 41.6 \mathrm{~mm}$ \\
\hline $\begin{array}{l}\text { Anterior region } \\
\text { (film No. 1) }\end{array}$ & 19.1 & 122 & 64.5 & -- \\
\hline $\begin{array}{l}\text { Posterior region } \\
\text { (film No. 2) }\end{array}$ & 25.3 & 16.2 & - & 58.1 \\
\hline
\end{tabular}

Table VI. Reduction of the irradiated area at the plane of the film by the use of aiming devices with a collimator plate

\begin{tabular}{|c|c|c|c|c|c|}
\hline & \multicolumn{3}{|c|}{ Irradiated area $\left(\mathrm{mm}^{2}\right)$} & \multirow{2}{*}{\multicolumn{2}{|c|}{$\begin{array}{l}\text { Reduction } \\
\text { (percent) }\end{array}$}} \\
\hline & \multicolumn{2}{|c|}{ ICRP ${ }^{9}$} & \multirow{2}{*}{$\begin{array}{l}\text { Aiming } \\
\text { device }\end{array}$} & & \\
\hline & $\operatorname{Min}$ & $\operatorname{Max}$ & & $\operatorname{Min}$ & $\operatorname{Max}$. \\
\hline $\begin{array}{l}\text { Anterior region } \\
\text { (film No. 1) }\end{array}$ & 50.20 & 78.20 & 14.90 & 70.4 & 81.0 \\
\hline $\begin{array}{l}\text { Posterior region } \\
\text { (film No. } 2)\end{array}$ & 50.20 & 78.20 & 21.80 & 56.5 & 72.1 \\
\hline
\end{tabular}

the plate were adjusted accordingly to 30.5 by 41.6 $\mathrm{mm}$. . resulting in an irradiated area of 40 by $54,6 \mathrm{~mm}$. at the film plane. With Size 2 films $(31$ by $41 \mathrm{~mm})$. 58.1 percent of the transmitted radiation is used to expose the film

For a comparison. Table $\mathrm{V}$ gives the percentages radiation used to expose the $x$-ray film for the reduced field sizes of the aiming devices and for the field sizes according to the ICRP requirements. The calculations were made for a long-tube $x$-ray unit with a focal-spotto-tube-end distance of $300 \mathrm{~mm}$. and a tube-end-to-film distance of $100 \mathrm{~mm}$. In all situations, the film is placed perpendicular to the central ray of the $x$-ray beam. 

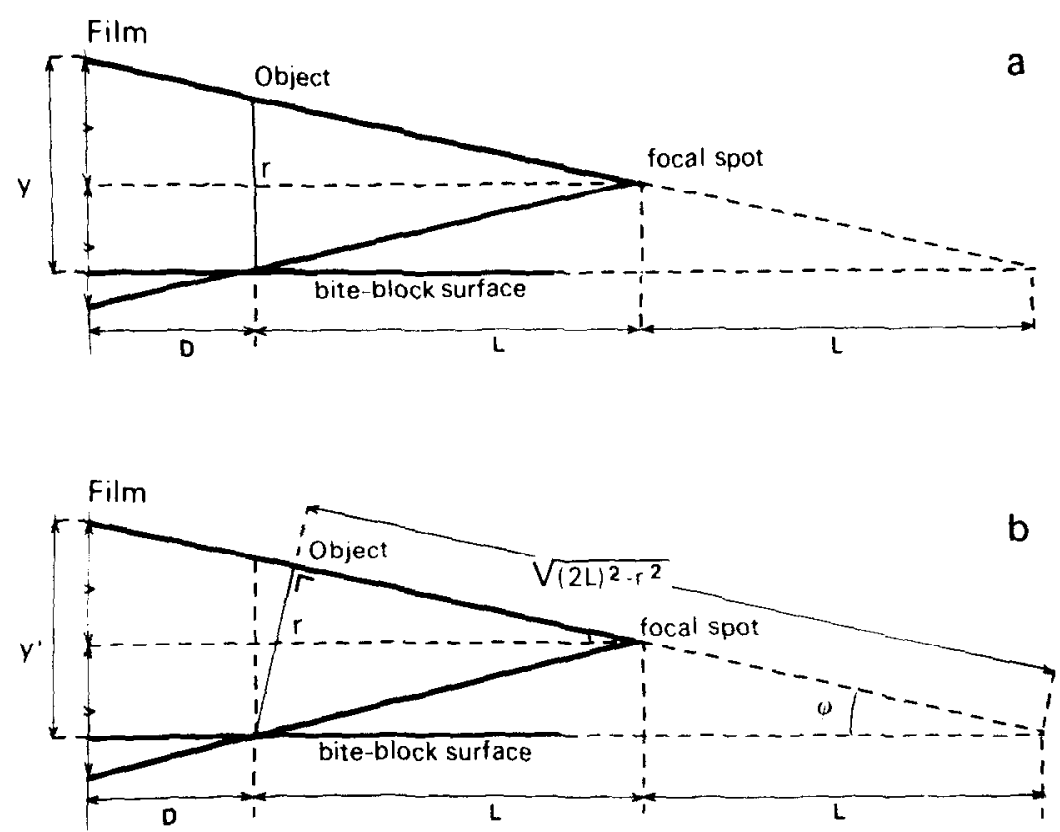

Fig. 10. a, Ratio $\frac{y}{r}$ when the relevant tooth dimension $(r)$ is perpendicular to the bite block. $\mathbf{b}$, Ratio $\mathrm{y}^{\prime}$ when the relevant tooth dimension $(r)$ is perpendicular to the ray projecting the apex, resulting in a maximum value for $y$ denoted by $y^{\prime} . L$. Focal spot-object distance. D. Object-film distance. $r$, Length of the tooth (r.r.1.). $y ; y^{\prime}$. Length of the part of the image projecting above the occlusal surface of the bite block.

It should be noted that, for roentgenograms made without the aiming devices, the distance from the tube end to the film is not fixed at $100 \mathrm{~mm}$. but varies with circumstances and that the film is not always perpendicular to the beam axis. The first aspect results in a somewhat higher percentage of radiation utilization ( 5 to 10 percent), whereas the second aspect will reduce this percentage.

\section{CONCLUSIONS}

The application of the described set of aiming devices (Fig. 2) with the film placed in the prescribed position (Fig. 7) makes it possible to obtain roentgenograns of high diagnostic value. The restriction of the field of irradiation to a size matching the film, which is much smaller than the maximum size permitted by the ICRP, results for the patient in an important reduction in the integral absorbed dose (Table VI).

\section{SUMMARY}

The factors influencing the design of aiming devices for intraoral radiography are described. The data obtained from the literature and from new measurements are used for the design of the bite blnck and the collimator plate of these devices. For the bite block, the following factors were found to be of importance (Fig. 3): (a) the length of the teeth to be radiographed; (b) the enlargement of the teeth as a result of the divergence of the $\mathrm{x}$-ray beam; (c) the desired periapical area to be visible; and (d) the amount of film, which is lost for the interpretation by the mounting of the roentgenograms.

Considering these factors, it was possible to determine the amount of film that should stand out above the occlusal surface of the bite block. Finally, the part of the film which has to submerge in the bite block was calculated. The results were differentiated for the different regions of the mouth to be radiographed and for both sexes. A description is given of the design of a bite block which permits, for practical reasons, three vertical film positions matching the above-mentioned groups.

The use of a collimator plate with a rectangular opening restricts the irradiation of the patient to an area matching the size of the film. This collimator plate also facilitates the aligning procedure. For the collimator plate, the following factors were found to be of importance: (a) the material used for the construction of the plate and its thickness; (b) the size of the plate; and (c) the dimensions of the opening in the collimator plate.

\section{REFERENCES}

1. Aken, J. van: Optimum Conditions for Intraoral Roentgenograms. ORAL SURG. 27: 475. 1969.

2. Barr, J. H.: An Effective and Practical Roentgenographic Technique, J. Can. Dent. Assoc. 21: 30, 1955.

3. Wuehrmann, A. H. Fvaluation Criteria for Intraoral Radiographic Film Quality, J. Am. Dent. Assoc. 89: 345, 1974.

4. Barr, J. H., and Gron, P.: Palate Contour as a Limiting Factor in Intraoral X-ray Technique, OraL Surg. 12: 459, 1959.

5. Updegrave, W. J.: The Paralleling Extension Cone Technique in intraoral Dental Radiography, ORAL SURG. 4: 1250, 1951. 
6. Updegrawe, W. J.: New Horizons in Periapical and Interponxtmal Radiography. Elgin, 1971. Rinn Corporation

1. Stephens. R. G. and Barr. J. H.: Anatomic Limitations in (1)traoral Roentgenography of the Upper Molar Region. Oral. SeRG. 8: 1272.1955 .

8. Verhoeven. J. W. Aken. J. van. and Weerdt. G. P. van der: The Length of Teeth: A Statisticat Analysis of the Difference in length of Human Teeth for Radiological Purposes. Oral. SI 'Ro; 47: 193-199. 1979

9. International Commission on Radiological Protection: Protection Against Ionizing Radiation From External Sources. ICRP Publi cation 15, Oxford. 1969. Pergamon Pres.

\section{APPENDIX}

1.A. The "object enlargement" (ratos $\frac{y}{\mathrm{r}}$ ), when the r.l. is perpendicular to the bite-block surface (Fig. 10. a). can bo obtained with the following equation:

$$
\frac{y}{r}=\frac{2 L+D}{2 L}
$$

1.B. The maximum "object enlargement" (ratio $\frac{y}{\mathrm{r}}$ ). when the r.r.l. is perpendicular to the ray projecting the apex (Fig. 10.b). is found by using the following cquations:
10. International (Organization tor Standardization: International Standard for Intraoral Dental Radiographic Film. ISO 3665. 1976.

Reprim fequtest:

Dr. J. lan Aken

Department of Oral Roentgenolog:

University of Utrecht Dental School

Sorbonnelian 16

3,508 TB Utrecht. The Nethertands

$$
\lg \phi=\frac{\mathrm{r}}{\sqrt{(2 \mathrm{~L})^{2}-\mathrm{r}^{2}}}=\frac{\mathrm{y}}{2 \mathrm{~L}+\mathrm{D}}
$$

Thus

$$
r-\frac{2 L+D}{\sqrt{(2 L)^{2}-r^{2}}}
$$

2. The following cquations explain the relation between $y$ and $s$ as uned in Fing, 6 :

$$
\begin{aligned}
& \text { Fran Fig } 3:-\mathrm{i} \cdots \mathrm{H}+\mathrm{v} \\
& \text { and } \quad H=y+R+m \\
& \text { therefore } \quad \because 1+1 \cdots y-\mathrm{R}-\mathrm{m}
\end{aligned}
$$

\section{INFORMATION FOR AUTHORS}

Most of the provisions of the Copyright $\Lambda \mathrm{ct}$ of 1976 became effective on January 1, 1978. Therefore, all manuscripts must be accompanied by the following written statement, signed by one author: "The undersigned author transfers all copyright ownership of the manuscript entitled (title of article) to The C. V. Mosby Company in the event the work is published. The undersigned author warrants that the articte is original. is not under consideration by another journal, and has not been previously published. I sign for and accept responsibility for releasing this material on behalf of any and all co-iuthors. "Authors will be consulted, when possible, regarding republication of their material. 